\title{
JNK and NF-кB signaling pathways are involved in cytokine changes in patients with congenital heart disease prior to and after transcatheter closure
}

\author{
SHUNYANG FAN ${ }^{1 *}$, KEFANG LI $^{1 *}$, DEYIN ZHANG ${ }^{2}$ and FUYUN LIU ${ }^{3}$ \\ ${ }^{1}$ Heart Center, The Third Affiliated Hospital of Zhengzhou University, Zhengzhou, Henan 450052; \\ ${ }^{2}$ Department of Internal Medicine, The Third People's Hospital of Henan Province, Zhengzhou, Henan 450000; \\ ${ }^{3}$ Department of Pediatric Surgery, The Third Affiliated Hospital of Zhengzhou University, \\ Zhengzhou, Henan 450052, P.R. China
}

Received December 15, 2016; Accepted August 26, 2017

DOI: $10.3892 /$ etm.2017.5595

\begin{abstract}
Congenital heart disease (CHD) is a problem in the structure of the heart that is present at birth. Due to advances in interventional cardiology, CHD may currently be without surgery. The present study aimed to explore the molecular mechanism underlying CHD. A total of 200 cases of CHD treated by transcatheter closure as well as 200 controls were retrospectively assessed. Serum cytokines prior to and after treatment were assessed by reverse-transcription quantitative polymerase chain reaction analysis. Furthermore, the levels of proteins associated with c-Jun N-terminal kinase (JNK) and nuclear factor $(\mathrm{NF})-\kappa \mathrm{B}$ were assessed by western blot analysis and immunohistochemistry. Furthermore, an animal model of CHD in young pigs was successfully constructed and treated with inhibitors of JNK and/or NF- $\mathrm{BB}$ to investigate the roles of these pathways in CHD. The results revealed that tumor necrosis factor- $\alpha$, interleukin (IL)- 6 and IL- 8 were significantly elevated in the experimental group following transcatheter closure treatment, compared with those in the healthy control group, and the serum levels of the anti-inflammatory cytokine IL-10 were significantly reduced. Phosphorylated c-Jun and p65 levels in the experimental group were notably higher in the experimental group compared with the control group, but were restored to normal levels following transcatheter closure treatment. Similar results were also obtained in the pig model. The results of the present study suggested that the CHD-associated
\end{abstract}

Correspondence to: Dr Fuyun Liu, Department of Pediatric Surgery, The Third Affiliated Hospital of Zhengzhou University, 7 Kangfuqian Road, Zhengzhou, Henan 450052, P.R. China

E-mail: fuyunliu111@126.com

${ }^{*}$ Contributed equally

Key words: congenital heart disease, transcatheter closure, cytokines, animal model, nuclear factor- $\kappa \mathrm{B}$ signaling pathway, c-Jun $\mathrm{N}$-terminal kinase signaling pathway changes in cytokines, as well as their recovery following transcatheter closure treatment were associated with the JNK and $\mathrm{NF}_{-} \kappa \mathrm{B}$ signaling pathways. The present study may provide further understanding of the underlying molecular mechanisms in CHD and propose a potential novel target for the treatment of CHD.

\section{Introduction}

Congenital heart disease (CHD), also known as a congenital heart anomaly, is a structural aberration of the heart that exists at birth (1). Its symptoms depend on the specific type of anomaly and therefore symptoms may vary widely, ranging from none to those of life-threatening severity (2). CHD is also a major cause of infant mortality worldwide (3). Previous studies have demonstrated that $28 \%$ of all major congenital anomalies consist of heart defects (4) and the most practical measurement of CHD occurrence is birth prevalence per 1,000 live births (5). The surveillance of birth defects in China revealed that in 1996 CHD was the 5th most common birth defect and it became the leading birth defect in 2009 (6-8).

At present, CHD is thought to be induced by genetic, lifestyle and environmental factors, including maternal obesity, diabetes, toxicant exposure and alterations in anti-oxidant capacity (9). These well-known risk factors are also associated with immune dysregulation (10). Due to advances in interventional cardiology, certain congenital heart anomalies no longer require surgical treatment and are treated via percutaneous interventions $(11,12)$. There have been numerous studies on CHD, however studies reporting on changes of inflammatory cytokines in patients with CHD following transcatheter closure treatment are lacking. It has been reported that CHD patients with a broad spectrum of pathologies demonstrated certain clinical features and a typical pattern of neurohormonal activation, which is characteristically found in chronic heart failure (CHF) (13). It still remains elusive whether the similarities between adult CHD and CHF extend to the inflammatory cytokine system (14). Certain studies reported that tumor necrosis factor (TNF)- $\alpha$ levels were elevated in a small pediatric cohort with CHD (15). However, only few 
studies have investigated the level of inflammatory cytokine system activity in CHD patients (16-23).

\section{Materials and methods}

Ethics statement. The present study was approved by the Ethics Committee of the Third Affiliated Hospital of Zhengzhou University (Zhengzhou, China). Written informed consent was provided by all subjects.

Subjects. A total of 200 consecutive patients with CHD

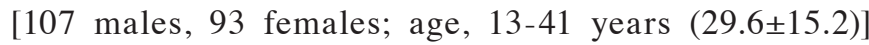
admitted to the Third Affiliated Hospital of Zhengzhou University (Zhengzhou, China) between September 2013 and February 2014 were included in this retrospective study. None of the patients had any unassociated abnormalities (not CDH-specific) or pulmonary hypertension. The cardiac diagnoses of all patients were made on the basis of clinical and laboratory examinations, including telecardiography, electrocardiography and echocardiography. The cases treated with transcatheter closure were retrospectively analyzed. Results prior to treatment as well as those at 6 and 12 months were included. Control data were taken from 200 normal individuals [110 males and 90 females; age, 12-39 years (25.42 \pm 13.28$)]$ who received a physical examination at the Third Affiliated Hospital of Zhengzhou University between September 2013 and February 2014.

Fasting blood samples were obtained and collected from the antecubital vein using a lightly fitting tourniquet. Blood $(3 \mathrm{ml})$ was drawn from each subject after fasting for $12 \mathrm{~h}$. Samples were collected in a sterile tube and sera were obtained immediately after clotting of samples, filled in sterile tubes and stored at $-80^{\circ} \mathrm{C}$ until use.

Serum biochemical analyses. TNF- $\alpha$ (cat. no. DTA00C), interleukin (IL)-6 (cat. no. D6050), IL-8 (cat. no. DY208) and IL-10 (cat. no. D1000B) levels were measured using commercially available ELISA assay kits (R\&D Systems, Minneapolis, MN, USA). The results are presented in $\mathrm{pg} / \mathrm{ml}$ or $\mathrm{U} / \mathrm{l}$.

Reverse-transcription quantitative polymerase chain reaction (RT-qPCR) analysis. Total RNA was extracted from the serum of subjects from the experimental group and the control group using an RNA extraction kit (cat. no. DP412; Tiangen Biotech Co., Ltd., Beijing, China) according to the manufacturer's protocol. Detection of the copy number of the mRNA of cytokines was performed as previously described (24).

Immunohistochemical (IHC) staining. Randomly selected samples of peripheral blood mononuclear cells were subjected to IHC staining and detection. IHC was performed as previously described (25).

Western blot analysis. Total protein was extracted and quantitated using a BCA Protein Assay reagent (Pierce; Thermo Fisher Scientific, Inc., Waltham, MA, USA). Western blot analysis was performed as previously described (25). The membranes were incubated at $4^{\circ} \mathrm{C}$ overnight with the following primary antibodies: Anti-c-Jun antibody $(1: 1,000$; ab32137), anti-p-c-Jun antibody (1:1,000; ab32385), anti-IKBa
Table I. Characteristics of patients in the experimental group and control group at baseline.

\begin{tabular}{lcc}
\hline Characteristic & Experimental group & Control group \\
\hline Sex & & \\
Male & 107 & 110 \\
Female & 93 & 90 \\
Age (years) & $29.6 \pm 15.2$ & $25.42 \pm 13.28$ \\
Height $(\mathrm{cm})$ & $172 \pm 10.13$ & $175 \pm 9.26$ \\
Body weight $(\mathrm{kg})$ & $65.2 \pm 10.15$ & $68.6 \pm 14.5$ \\
\hline
\end{tabular}

Values are expressed as $\mathrm{n}$ or as the mean \pm standard deviation.

antibody (1:1,000; ab32518), anti-p-IKB $\alpha$ antibody (1:10,000; (ab133462), anti-P65 antibody (2.5 $\mu \mathrm{g} / \mathrm{ml}$; ab19870), anti-p-P65 antibody (1:10,000; ab76302) (all from Abcam, Cambridge, MA, USA). This was followed by incubation with the corresponding horseradish peroxidase-conjugated secondary antibodies: anti-rabbit (ab6721) or anti-mouse (ab6785) immunoglobulin G antibodies (both 1:5,000; Beyotime Institute of Biotechnology, Haimen, China) at $37^{\circ} \mathrm{C}$ for $45 \mathrm{~min}$. The target bands were visualized by using an enhanced chemiluminescence kit (Qihai Biotech, Shanghai, China) and the associated band intensities were analyzed using Gel-Pro-Analyzer software version 4.0 (Media Cybernetics, Inc., Rockville, MD, USA). $\beta$-actin was used as the internal control.

Animal model of CHD. A hybrid method was employed to generate the animal model of CHD in young pigs, as previously described (26). A total of 50 animals (4-8 weeks old; $10-12 \mathrm{~kg}$ ) were provided by the Third Affiliated Hospital of Zhengzhou University (Zhengzhou, China), CHD was successfully induced in 43 animals and 40 animals were divided into four groups ( $\mathrm{n}=10 /$ group) with 3 animals in reserve. All animals were housed in isolated cages under a $12 \mathrm{~h}$ light/dark cycle at $23-25^{\circ} \mathrm{C}$, humidity $50-70 \%$ with free access to food and water according to the Guide for the Care and Use of Laboratory Animals (27). A group of 10 normal young pigs was used for determination of serum cytokine levels as a blank control group. Over 3 months following surgery, a group of CHD model animals with catheter closure treatment received continuous injection of normal saline as a control group. A second group of the CHD models received continuous injection of pyrrolidine dithiocarbamate (PDTC; Sigma-Aldrich; Merck KGaA, Darmstadt, Germany), a nuclear factor (NF)- $\kappa$ B inhibitor, over 3 months following catheter closure treatment. Another group of CHD models received continuous injection of SP600125 (Sigma-Aldrich; Merck KGaA), a c-Jun N-terminal kinase (JNK) inhibitor, and a further group of CHD models received continuous combined injection of PDTC and SP600125 over 3 months following catheter closure treatment. All animal protocols were reviewed and approved by the Institutional Animal Care and Use Committee of the Third Affiliated Hospital of Zhengzhou University (Zhengzhou, China).

Statistical analysis. Quantitative data are expressed as the mean \pm standard deviation. SPSS 18.0 (SPSS, Inc., Chicago, 
Table II. Serum cytokine levels in patients with congenital heart disease prior to and after transcatheter closure treatment as well as in the control group.

Experimental group

\begin{tabular}{lcrrr}
\cline { 3 - 4 } Cytokine & Control & Baseline & 6 months & 12 months \\
\hline TNF- $\alpha$ & $877 \pm 129$ & $1,936 \pm 214^{\mathrm{a}}$ & $1,311 \pm 211^{\mathrm{a}}$ & $866 \pm 242$ \\
IL-6 & $599 \pm 289$ & $1,699 \pm 299^{\mathrm{a}}$ & $1,196 \pm 313^{\mathrm{a}}$ & $561 \pm 189$ \\
IL-8 & $623 \pm 92$ & $1,268 \pm 104^{\mathrm{a}}$ & $972 \pm 272^{\mathrm{a}}$ & $413 \pm 113^{\mathrm{a}}$ \\
IL-10 & $1,191 \pm 296$ & $499 \pm 211^{\mathrm{a}}$ & $791 \pm 363^{\mathrm{a}}$ & $1,278 \pm 202$ \\
\hline
\end{tabular}

${ }^{\mathrm{a}} \mathrm{P}<0.05$ vs. Control. TNF, tumor necrosis factor; IL, interleukin.

IL, USA) was used for all statistical analyses. Comparison between two groups was performed using Student's t-test. Comparisons among three or more groups were performed using one-way analysis of variance followed by Tukey's post hoc test. $\mathrm{P}<0.05$ was considered to indicate a statistically significant difference.

\section{Results}

Clinical characteristics of patients. All 200 cases of CHD were subjected to transcatheter closure treatment at the Third Affiliated Hospital of Zhengzhou University (Zhengzhou, China) between September 2013 and February 2014. The baseline patient characteristics are presented in Table I. The mean patient age in the experimental group was $29.6 \pm 15.2$ years and that in the control group was $65.42 \pm 3.28$ years.

Transcatheter closure treatment restores cytokine levels in CHD patients. Peripheral blood mononuclear cell samples and serum were obtained from patients in the experimental group and the control group. ELISA demonstrated that serum inflammatory cytokine levels of TNF- $\alpha$, IL- 6 and IL- 8 in the experimental group after transcatheter closure treatment were significantly elevated compared with those in the healthy control group without treatment. Conversely, the serum levels of the anti-inflammatory cytokine IL-10 were significantly reduced. Of note, at 6 months and 12 months after transcatheter closure treatment, TNF- $\alpha$, IL- 6 and IL-8 levels in patients' serum were significantly reduced, and IL-10 rose compared with the control. The levels of all of the cytokines were nearly restored (Table II).

To further confirm the changes of cytokines in the patients, RT-qPCR was performed and the results demonstrated that the mRNA levels of TNF- $\alpha$, IL- 6 and IL- 8 in the experimental group were significantly upregulated, while those of IL-10 were significantly reduced compared with those in the control group. At 6 and 12 months after transcatheter closure treatment, the mRNA levels of TNF- $\alpha$, IL-6, IL- 8 and IL-10 returned to normal levels (Fig. 1).

To explore the molecular mechanisms associated with the changes in cytokine levels of CHD patients after transcatheter closure treatment, peripheral blood mononuclear cells were subjected to western blot analysis and IHC staining. The western blot results demonstrated that phosphorylated
(p)-c-Jun, p65 and p-IкBa levels in the experimental group were higher than in the control group, and were restored to normal levels after transcatheter closure treatment (Fig. 2). IHC analysis was conducted 6 months following treatment and the results indicated that the p-c-Jun- and p-65-positive cell rate in peripheral blood mononuclear cells was higher prior to treatment compared with that in the control group and decreased following treatment (Fig. 3). These results indicate that the $\mathrm{JNK}$ and $\mathrm{NF}-\kappa \mathrm{B}$ signaling pathways were activated in patients with $\mathrm{CHD}$, and that transcatheter closure treatment may notably decrease the activation of these pathways.

Animal model of CHD. Next, an animal model of CHD was successfully constructed in 40 young pigs via a hybrid method according to standard protocols and divided into four groups. The serum cytokine levels of TNF- $\alpha$, IL- 6 and IL-8 were elevated following transcatheter closure treatment, while the levels of the anti-inflammatory cytokine IL-10 dropped. Injection of PDTC (NF- $\mathrm{BB}$ inhibitor) or SP600125 (JNK inhibitor) alone only partly restored TNF- $\alpha$, IL-6, IL-8 or IL-10 compared with normal levels. Of note, combination treatment with PDTC and SP600125 restored TNF- $\alpha$, IL-6, IL- 8 and IL-10 to normal levels (Table III). These results suggested that the CHD-associated changes in cytokines as well as their recovery after transcatheter closure treatment are associated with the JNK and NF- $\mathrm{NB}$ signaling pathways.

\section{Discussion}

TNF- $\alpha$, IL-6, IL- 8 and IL-10 are important inflammatory or anti-inflammatory cytokines, which contribute to numerous signaling pathways $(\mathrm{JNK}, \mathrm{NF}-\kappa \mathrm{B})$ to regulate certain biological processes (28-33). The present study provided a better understanding of the roles of cytokines in patients with $\mathrm{CHD}$; the results indicated the presence of a certain degree of immune activation, causing an increase in the levels of inflammatory cytokines and a decrease in anti-inflammatory cytokine levels to result in inflammation. Following catheter closure treatment, the patients' immune and inflammatory status was gradually restored to normal levels.

An increasing number of studies have demonstrated that the occurrence of inflammation is closely associated with the expression of genes linked to inflammation $(34,35)$. The 
Table III. Levels of cytokines in the model of congenital heart disease in young pigs.

Experimental group

\begin{tabular}{|c|c|c|c|c|c|}
\hline Cytokine & Control & Vehicle treated & PDTC & SP600125 & PDTC + SP600125 \\
\hline \multicolumn{6}{|l|}{ TNF- $\alpha$} \\
\hline Baseline & $689 \pm 172$ & $1,312 \pm 191^{\mathrm{a}}$ & $1,311 \pm 211^{\mathrm{a}}$ & $1,196 \pm 313^{\mathrm{a}}$ & $1,301 \pm 328^{a}$ \\
\hline 6 months & $691 \pm 296$ & $472 \pm 133$ & $984 \pm 191^{\mathrm{a}}$ & $967 \pm 211^{\mathrm{a}}$ & $456 \pm 98$ \\
\hline \multicolumn{6}{|l|}{ IL-6 } \\
\hline Baseline & $531 \pm 298$ & $1,699 \pm 299^{a}$ & $1,531 \pm 298^{\mathrm{a}}$ & $1,588 \pm 139^{\mathrm{a}}$ & $1,761 \pm 189^{a}$ \\
\hline 6 months & $581 \pm 112$ & $482 \pm 133$ & $884 \pm 11^{\mathrm{a}}$ & $867 \pm 111^{\mathrm{a}}$ & $456 \pm 98$ \\
\hline \multicolumn{6}{|l|}{ IL-8 } \\
\hline Baseline & $431 \pm 298$ & $1,788 \pm 299^{a}$ & $1,453 \pm 298^{a}$ & $1,688 \pm 139^{\mathrm{a}}$ & $1,861 \pm 189^{\mathrm{a}}$ \\
\hline 6 months & $481 \pm 112$ & $482 \pm 133$ & $974 \pm 11^{\mathrm{a}}$ & $967 \pm 111^{\mathrm{a}}$ & $356 \pm 98$ \\
\hline \multicolumn{6}{|l|}{ IL-10 } \\
\hline Baseline & $1,431 \pm 298$ & $288 \pm 29^{a}$ & $453 \pm 298^{a}$ & $488 \pm 139^{a}$ & $461 \pm 189^{a}$ \\
\hline 6 months & $1,481 \pm 112$ & $1,482 \pm 133$ & $974 \pm 113^{\mathrm{a}}$ & $967 \pm 111^{\mathrm{a}}$ & $1,356 \pm 98$ \\
\hline
\end{tabular}

${ }^{\text {aP }}<0.05$ vs. Control. TNF, tumor necrosis factor; IL, interleukin; PDTC, pyrrolidine dithiocarbamate.
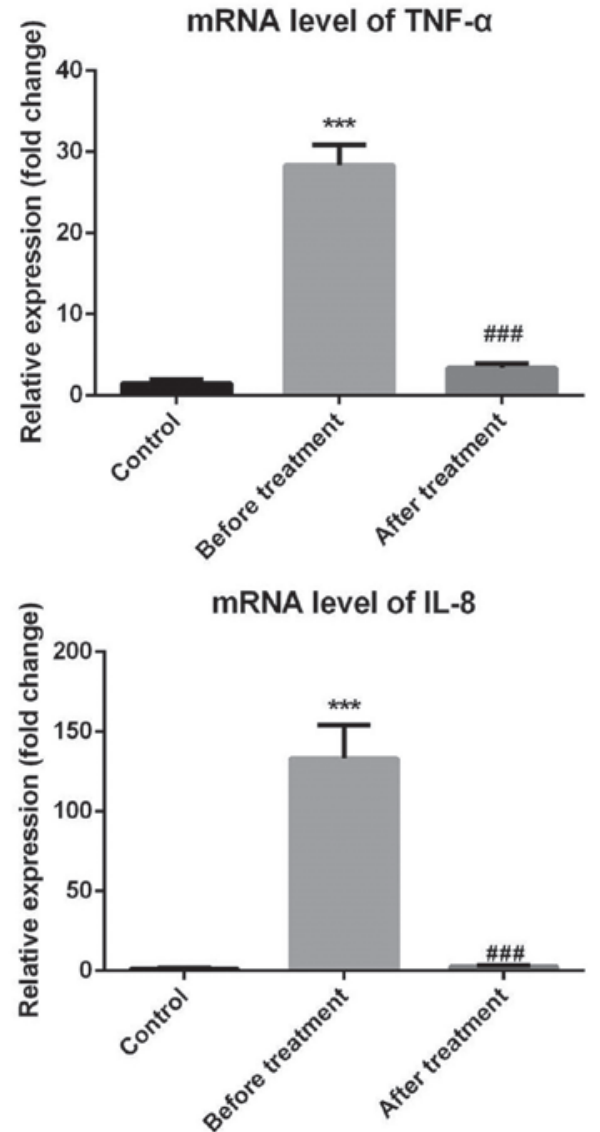
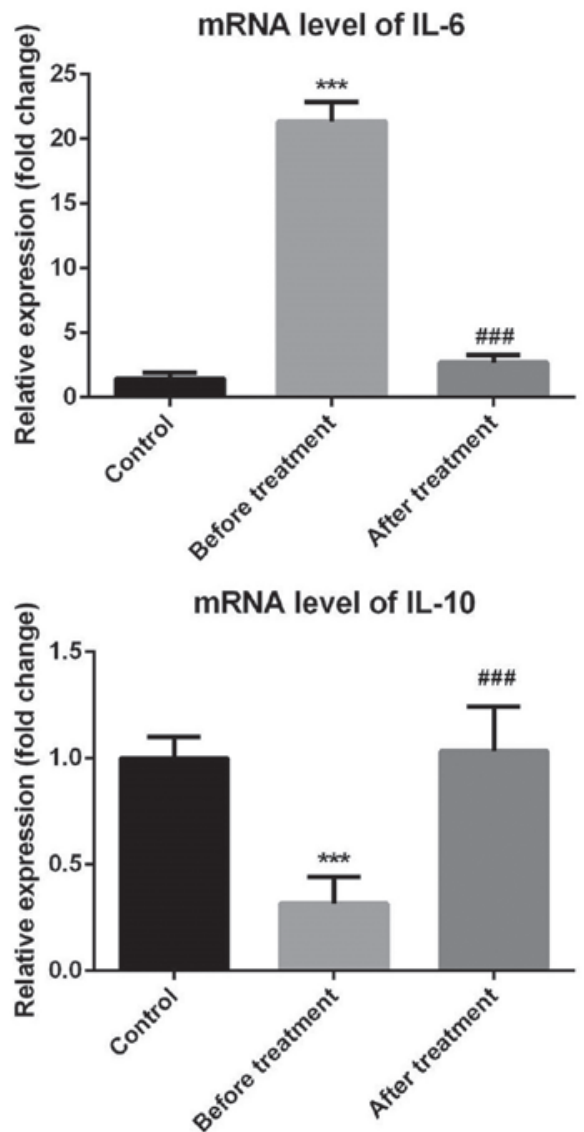

Figure 1. Cytokine mRNA levels prior to and following transcatheter closure treatment as well as in the control group. TNF, tumor necrosis factor; IL, interleukin. ${ }^{* * * *} \mathrm{P}<0.001$ vs. the control group; ${ }^{\# \#} \mathrm{P}<0.001$ vs. the before treatment group.

JNK (36-41) and NF-кB (42-47) signaling pathways are two important pathways that have roles in the occurrence and development of inflammation and are associated with heart diseases such as heart failure (48). Cytokine changes caused by CHD may synergistically occur via these two pathways $(48,49)$. Changes of cytokines in patients with CHD may be due to the coordination of members of the $N F-\kappa B$ and the JNK signaling pathway. Wang et al (50) demonstrated 

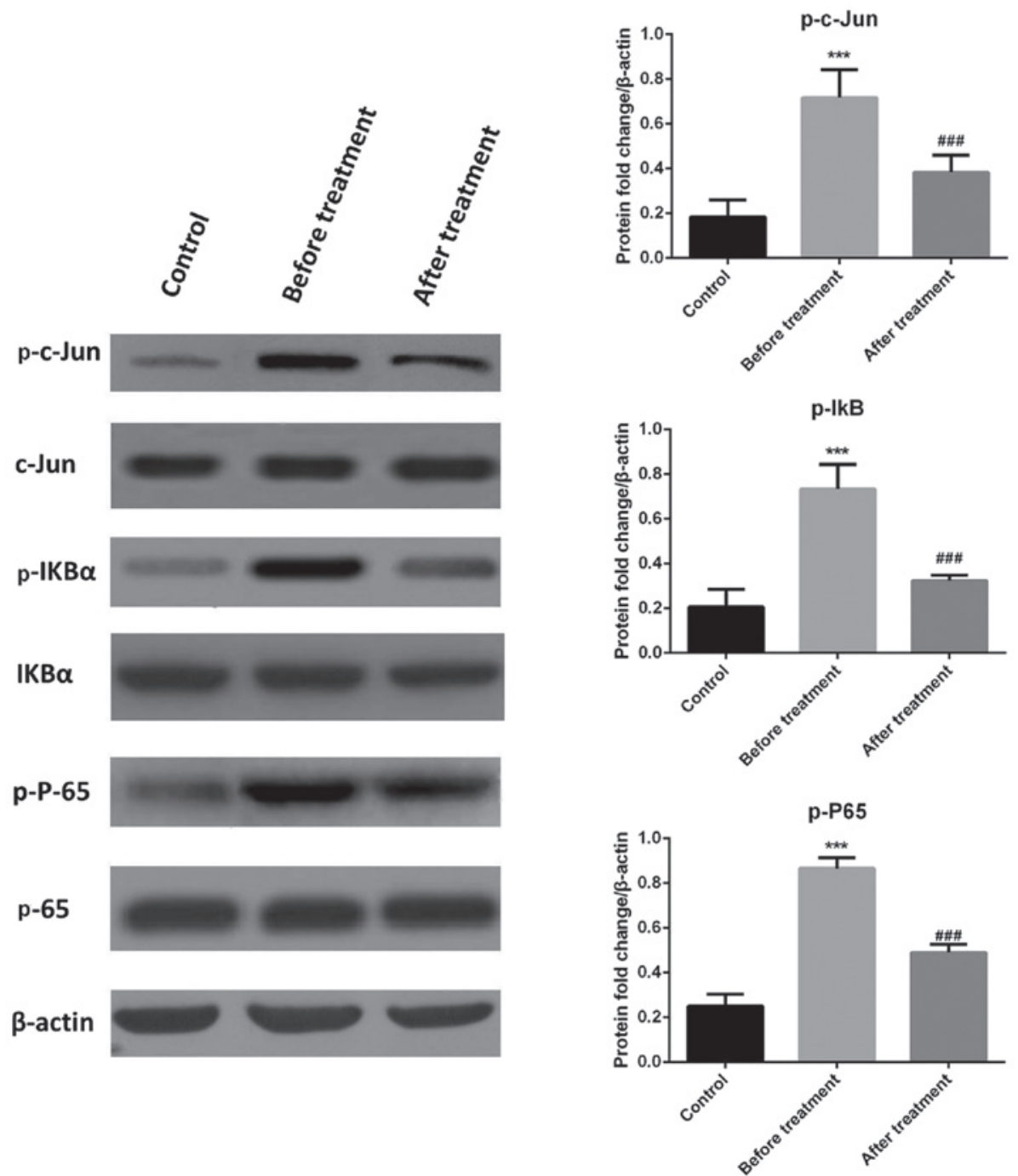

Figure 2. Levels of c-Jun N-terminal kinase and nuclear factor- $\mathrm{KB}$ pathway proteins prior to and after transcatheter closure treatment as well as in the control group. p-IкB, phosphorylated inhibitor of nuclear factor $\kappa \mathrm{B} .{ }^{* * * *} \mathrm{P}<0.001$ vs. the control group; ${ }^{\# \# t ~} \mathrm{P}<0.001$ vs. the before treatment group.

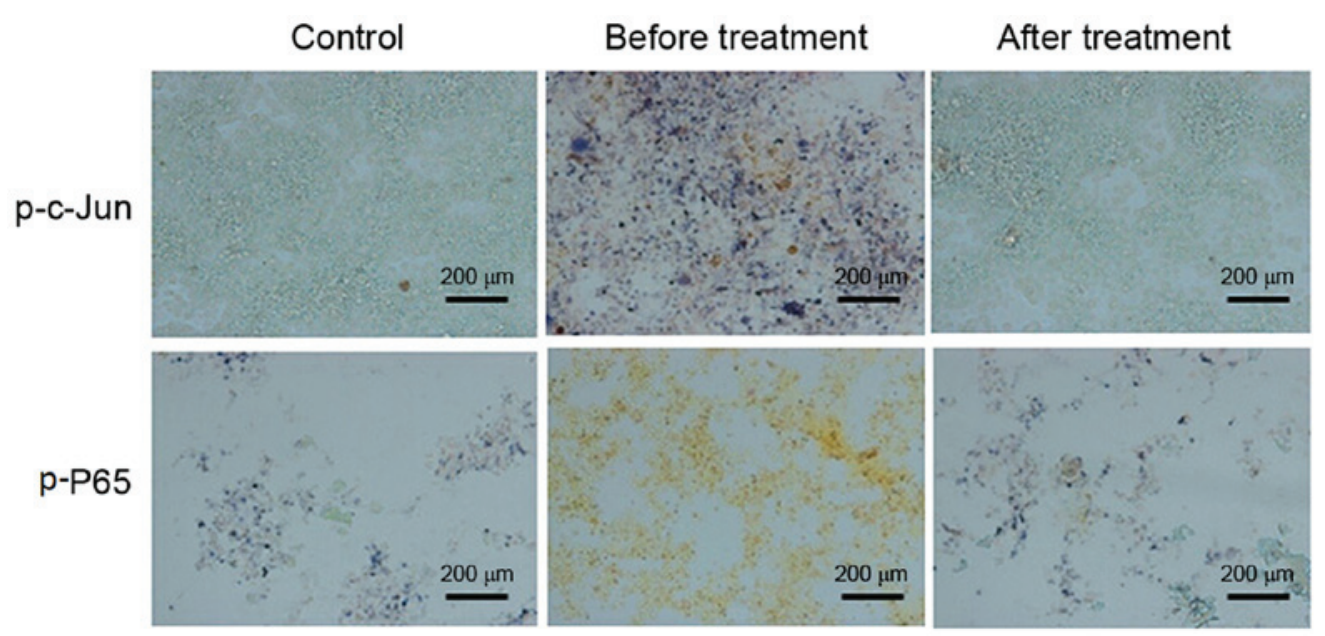

Figure 3. Immunostaining for p-P65 and p-c-Jun in the experimental and control groups 6 months following transcatheter closure treatment (scale bar, $200 \mu \mathrm{m})$. p, phosphorylated.

that fasudil hydrochloride hydrate, a rho-kinase inhibitor, suppressed isoproterenol-induced heart failure in rats via the JNK and Extracellular signal-regulated kinase 1/2 signaling pathways. Gu et al (51) demonstrated that hypoxia-induced SOCS3 inhibited NF- $\mathrm{B}$ activation in congenital heart disease. 
Of note, the NF- $\kappa \mathrm{B}$ and JNK signaling pathways were not activated in patients with CHD following transcatheter closure treatment. To a certain degree, the abnormal changes of cytokines in patients with CHD and their recovery following transcatheter closure treatment are dependent on the coordination of JNK and NF- $\kappa \mathrm{B}$ signaling pathways.

The present study had certain limitations. Sampling of a larger amount of serum from the same patient with CHD would have been more beneficial to assess more cytokines to better elucidate the potential underlying mechanism.

In conclusion, the results of the present study suggested a certain degree of immune activation in patients with CHD, resulting in an increase in inflammatory cytokine levels and a decrease in anti-inflammatory cytokine levels. Transcatheter closure treatment gradually restored the patients' inflammatory status. Changes in the levels of cytokines in patients with CHD may be regulated by the NF- $\kappa \mathrm{B}$ and JNK signaling pathways. Taken together, the results of the present study indicated that CHD is associated with an upregulated inflammatory response, providing a theoretical basis for further research.

\section{References}

1. Fahed AC, Gelb BD, Seidman JG and Seidman CE: Genetics of congenital heart disease: The glass half empty. Circ Res 112: 707-720, 2013

2. Alam AM, Ahmed I, Ahmed M, et al: Congenital heart surgery: Analysis of cases 130: 30, 2016.

3. Khairy P, Ionescu-Ittu R, Mackie AS, Abrahamowicz M, Pilote L and Marelli AJ: Changing mortality in congenital heart disease. J Am Coll Cardiol 56: 1149-1157, 2010.

4. Dolk H,Loane M and Garne E; European surveillance of congenital anomalies (EUROCAT) working group: Congenital heart defects in Europe: Prevalence and perinatal mortality, 2000 to 2005. Circulation 123: 841-849, 2011.

5. van der Linde D, Konings EE, Slager MA, Witsenburg M, Helbing WA, Takkenberg JJ and Roos-Hesselink JW: Birth prevalence of congenital heart disease worldwide: A systematic review and meta-analysis. J Am Coll Cardiol 58: 2241-2247, 2011

6. Rudan I, Chan KY, Zhang JS, Theodoratou E, Feng XL, Salomon JA, Lawn JE, Cousens S, Black RE, Guo Y, et al: Causes of deaths in children younger than 5 years in China in 2008. Lancet 375: 1083-1089, 2010.

7. Qu Y, Liu X, Zhuang J, Chen G, Mai J, Guo X, Ou Y, Chen J, Gong W, Gao X, et al: Incidence of congenital heart disease: The 9 -year experience of the guangdong registry of congenital heart disease, China. PLoS One 11: e0159257, 2016.

8. Dai L, Zhu J, Liang J, Wang YP, Wang H and Mao M: Birth defects surveillance in China. World J Pediatr 7: 302-310, 2011.

9. Zaidi S, Choi M, Wakimoto H, Ma L, Jiang J, Overton JD, Romano-Adesman A, Bjornson RD, Breitbart RE, Brown KK, et al: De novo mutations in histone-modifying genes in congenital heart disease. Nature 498: 220-223, 2013

10. Cole CR, Yutzey KE, Brar AK, Goessling LS, Van VickleChavez SJ, Cunningham MW and Eghtesady P: Congenital heart disease linked to maternal autoimmunity against cardiac myosin. J Immunol 192: 4074-4082, 2014.

11. Braunwald E and Bristow MR: Congestive heart failure: Fifty years of progress. Circulation 102 (20 Suppl 4): IV14-IV23, 2000.

12. Sharma R, Bolger AP, Li W, Davlouros PA, Volk HD, Poole-Wilson PA, Coats AJ, Gatzoulis MA and Anker SD: Elevated circulating levels of inflammatory cytokines and bacterial endotoxin in adults with congenital heart disease. Am J Cardiol 92: 188-193, 2003.

13. Bolger AP, Sharma R, Li W, Leenarts M, Kalra PR, Kemp M, Coats AJ, Anker SD and Gatzoulis MA: Neurohormonal activation and the chronic heart failure syndrome in adults with congenital heart disease. Circulation 106: 92-99, 2002.

14. Tatebe S, Fukumoto Y, Sugimura K, Miura Y, Nochioka K, Aoki T, Yamamoto $\mathrm{S}$ and Shimokawa $\mathrm{H}$ : Clinical profiles of chronic heart failure with adult congenital heart disease. J Cardiac Failure 18: S156, 2012.
15. Afify MF, Mohamed GB, El-Maboud MA and Abdel-Latif EA: Serum levels of ghrelin, tumor necrosis factor- $\alpha$ and interleukin-6 in infants and children with congenital heart disease. J Trop Pediatr 55: 388-392, 2009.

16. McMurray J, Abdullah I, Dargie HJ and Shapiro D: Increased concentrations of tumour necrosis factor in 'cachectic' patients with severe chronic heart failure. Br Heart J 66: 356-358, 1991.

17. Torre-Amione G, Kapadia S, Benedict C, Oral H, Young JB and Mann DL: Proinflammatory cytokine levels in patients with depressed left ventricular ejection fraction: A report from the studies of left ventricular dysfunction (SOLVD). J Am Coll Cardiol 27: 1201-1206, 1996.

18. Ferrari R, Bachetti T, Confortini R, Opasich C, Febo O, Corti A, Cassani $\mathrm{G}$ and Visioli O: Tumor necrosis factor soluble receptors in patients with various degrees of congestive heart failure. Circulation 92: 1479-1486, 1995.

19. Kubota T, Mctiernan CF, Frye CS, Slawson SE, Lemster BH, Koretsky AP, Demetris AJ and Feldman AM: Dilated cardiomyopathy in transgenic mice with cardiac-specific overexpression of tumor necrosis factor- $\alpha$. Circ Res 81: 627-635, 1997.

20. Borish L, Aarons A, Rumbyrt J, Cvietusa P, Negri J and Wenzel S: Interleukin-10 regulation in normal subjects and patients with asthma. J Allergy Clin Immunol 97: 1288-1296, 1996.

21. Gullestad L, Aass H, Fjeld JG, Wikeby L, Andreassen AK, Ihlen H, Simonsen S, Kjekshus J, Nitter-Hauge S, Ueland T, et al: Immunomodulating therapy with intravenous immunoglobulin in patients with chronic heart failure. Circulation 103: 220-225, 2001.

22. AukrustP,Ueland T,Lien E, Bendtzen K, MüllerF, Andreassen AK, Nordøy I, Aass H, Espevik T, Simonsen S, et al: Cytokine network in congestive heart failure secondary to ischemic or idiopathic dilated cardiomyopathy. Am J Cardiol 83: 376-382, 1999.

23. Kanda $\mathrm{T}$ and Takahashi T: Interleukin- 6 and cardiovascular diseases. Jpn Heart J 45: 183-193, 2004.

24. Latorre E, Mendoza C, Matheus N, Castro M, Grasa L, Mesonero JE and Alcalde AI: IL-10 modulates serotonin transporter activity and molecular expression in intestinal epithelial cells. Cytokine 61: 778-784, 2013.

25. Choi Y, Park J, Choi Y, Ko YS, Yu DA, Kim Y, Pyo JS, Jang BG, Kim MA, Kim WH and Lee BL: c-Jun N-terminal kinase activation has a prognostic implication and is negatively associated with FOXO1 activation in gastric cancer. Bmc Gastroenterol 16: 59, 2016.

26. Xu Y, Liu Y, Lv X, Yu C and Li X: A novel hybrid method for creating a porcine model of cyanotic congenital heart defect with decreased pulmonary blood flow. J Surg Res 154: 262-266, 2009.

27. National Research Council: Guide for the Care and Use of Laboratory Animals. 8th edition. National Academies Press (US), Washington, DC, pp267-268, 2012.

28. Ji RR, Gereau RW IV, Malcangio M and Strichartz GR: MAP kinase and pain. Brain Res Rev 60: 135-148, 2009.

29. Weston CR and Davis RJ: The JNK signal transduction pathway. Curr Opin Cell Biol 19: 142-149, 2007.

30. Liu J and Lin A: Role of JNK activation in apoptosis: A double-edged sword. Cell Res 15: 36-42, 2005.

31. Bogoyevitch MA and Kobe B: Uses for JNK: The many and varied substrates of the c-Jun N-terminal kinases. Microbiol Mol Biol Rev 70: 1061-1095, 2006.

32. Akella R, Moon TM and Goldsmith EJ: Unique MAP Kinase binding sites. Biochim Biophys Acta 1784: 48-55, 2008.

33. Brown MD and Sacks DB: Protein scaffolds in MAP kinase signalling. Cell Signal 21: 462-469, 2009.

34. Monroy CM, Cortes AC, Lopez MS, D'Amelio AM Jr, Etzel CJ, Younes A, Strom SS and El-Zein RA: Hodgkin disease risk: Role of genetic polymorphisms and gene-gene interactions in inflammation pathway genes. Mol Carcinog 50: 36-46, 2011.

35. Yang X, Lu H, Yan B, Romano RA, Bian Y, Friedman J, Duggal P, Allen C, Chuang R, Ehsanian R, et al: $\Delta \mathrm{Np} 63$ versatilely regulates a Broad NF- $\kappa \mathrm{B}$ gene program and promotes squamous epithelial proliferation, migration, and inflammation. Cancer Res 71: 3688-3700, 2011.

36. Karin M, Lawrence $\mathrm{T}$ and Nizet V: Innate immunity gone awry: Linking microbial infections to chronic inflammation and cancer. Cell 124: 823-835, 2006.

37. Slevin M, Elasbali AB, Miguel Turu M, Krupinski J, Badimon L and Gaffney J: Identification of differential protein expression associated with development of unstable human carotid plaques. Am J Pathol 168: 1004-1021, 2006.

38. Wilhelm M, Xu Z, Kukekov NV, Gire S and Greene LA: Proapoptotic Nix activates the JNK pathway by interacting with POSH and mediates death in a Parkinson disease model. J Biol Chem 282: 1288-1295, 2007. 
39. Smith WW, Gorospe M and Kusiak JW: Signaling mechanisms underlying Abeta toxicity: Potential therapeutic targets for Alzheimer's disease. Cns Neurol Disord Drug Targets 5: 355-361, 2006.

40. Størling J, Binzer J, Andersson AK, Züllig RA, Tonnesen M, Lehmann R, Spinas GA, Sandler S, Billestrup N and MandrupPoulsen T: Nitric oxide contributes to cytokine-induced apoptosis in pancreatic beta cells via potentiation of JNK activity and inhibition of Akt. Diabetologia 48: 2039-2050, 2005.

41. Tuncman G, Hirosumi J, Solinas G, Chang L, Karin M and Hotamisligil GS: Functional in vivo interactions between JNK1 and JNK2 isoforms in obesity and insulin resistance. Proc Natl Acad Sci USA 103: 10741-10746, 2006.

42. Sen R and Baltimore D: Multiple nuclear factors interact with the immunoglobulin enhancer sequences. Cell 177: 7485-7496, 2006.

43. Deswal A, Petersen NJ, Feldman AM, Young JB, White BG and Mann DL: Cytokines and cytokine receptors in advanced heart failure: An analysis of the cytokine database from the Vesnarinone trial (VEST). Circulation 103: 2055-2059, 2001.

44. Valen G, Yan ZQ and Hansson GK: Nuclear factor kappa-B and the heart. J Am Coll Cardiol 38: 307-314, 2001.

45. Cohn JN, Ferrari R and Sharpe N: Cardiac remodeling-concepts and clinical implications: A consensus paper from an international forum on cardiac remodeling. Behalf of an international forum on cardiac remodeling. J Am Coll Cardiol 35: 569-582, 2000.
46. Haudek SB, Bryant DD and Giroir BP: Differential regulation of myocardial NF kappa B following acute or chronic TNF-alpha exposure. J Mol Cell Cardiol 33: 1263-1271, 2001.

47. Bradham WS, Moe G, Wendt KA, Scott AA, Konig A, Romanova M, Naik G and Spinale FG: TNF- $\alpha$ and myocardial matrix metalloproteinases in heart failure: Relationship to LV remodeling. Am J Physiol Heart Circ Physiol 282: H1288-H1295, 2002.

48. Lagyal CM, Guia TD, Ayuyao F and Bautista M: Prolonged mechanical ventilation among children with congenital heart disease undergoing cardiac surgery in philippine heart center: A risk factors analysis. Am J Respir Crit Care Med 183: A1700, 2011.

49. Hamid T, Gu Y, Ortines RV, Bhattacharya C, Wang G, Xuan YT and Prabhu SD: Divergent tumor necrosis factor receptor-related remodeling responses in heart failure: Role of nuclear factor-kappaB and inflammatory activation. Circulation 119: 1386-1397, 2009.

50. Wang N, Guan P, Zhang JP, Li YQ, Chang YZ, Shi ZH, Wang FY and Chu L: Fasudil hydrochloride hydrate, a Rho-kinase inhibitor, suppresses isoproterenol-induced heart failure in rats via JNK and ERK1/2 pathways. J Cell Biochem 112: 1920-1929, 2011.

51. Gu Q, Kong Y, Yu ZB, Bai L and Xiao YB: Hypoxia-induced SOCS3 is limiting STAT3 phosphorylation and NF- $\kappa$ B activation in congenital heart disease. Biochimie 93: 909-920, 2011. 